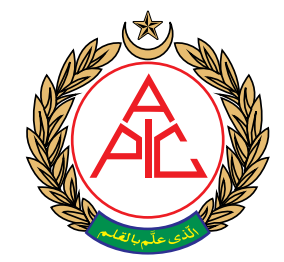

${ }^{1}$ Department of Anesthesiology and Reanimation, Sakarya University Education and Research Hospital, Sakarya, (Turkey)

2Department of Hematology, Sakarya University Faculty of Medicine, Sakarya, (Turkey) Correspondence:

Tolga Ergonenc, MD, Department of Anesthesiology and Reanimation, Sakarya University Education and

Research Hospital, Akyazı Pain Center, Sakarya, (Turkey) tolgaergonenc@gmail.com, ORCID https://orcid.org/00000002-4325-695X

\section{New coronavirus disease (COVID-19): A perspective from Turkey}

\author{
Tolga Ergonenc ${ }^{1}$, Tuba Hacibekiroglu ${ }^{2}$
}

\section{ABSTRACT}

\begin{abstract}
The new coronavirus (COVID-19), which causes severe respiratory diseases such as pneumonia and lung failure, is spreading Since December 2019, across the globe from China rapidly. While global institutions and companies have focused on developing vaccines for the prevention of COVID-19, no specific vaccine has yet been found.

In this perspective review, we highlight the current status of epidemiology, diagnosis, treatment, and transmission to control the spread of this virus disease from the perspective of Turkey.
\end{abstract}

Key words: Coronavirus, COVID-19, outbreak, pneumonia, convalescent plasma

Citation: Ergonenc T, Hacibekiroglu T. New coronavirus disease (COVID-19): A perspective from Turkey. Anaesth. pain intensive care 2020;24(2):132-137 DOL: https://doi.org/10.35975/apic.v24i2.1250
On 30 January 2020, the World Health Organization (WHO) declared the severe acute respiratory syndrome caused by the new coronavirus (COVID-19) that first appeared in Wuhan, China, as a public health emergency of international. ${ }^{1}$ COVID-19 was declared as a pandemic by the WHO on 11 March $2020 .^{2}$ Since December 2019, the rapid spread of COVID-19 to over $2,240,000$ people in 184 countries, caused more than 152,000 deaths. ${ }^{3}$

COVID-19 is transmitted through droplets, respiratory secretions, and direct contact. Aerosols arise during coughing and sneezing. Not only symptomatic patients spread the virus, but asymptomatic people can also spread the virus before the onset of symptoms. ${ }^{4}$ Aerosols can spread 1-2 $\mathrm{m}$ and droplets can deposit on surfaces. COVID-19, which is in droplets, can remain viable on different surfaces for a couple of days in suitable conditions. The fecal-oral route is suspected to be another spreading route because some patients with infected by COVID19 , have the live infectious virus present in their feces. ${ }^{5}$ Disinfectants such as sodium hypochlorite, hydrogen peroxide, and alcohol have a destructive effect on the virus.

Healthcare professionals and researchers in all disciplines must be aware of the impact of COVID-19 on their field and the medical community. Dependent on the literature, we systematically discuss COVID-19 treatment from the Turkish perspective, hoping to provide a reference for future studies and help prevent and control the COVID-19.

\section{PREVENTION}

Due to the potential infectivity before the appearance of the symptoms during the incubation period, spread from asymptomatic people, prolonged incubation time, conjunctival transmission, long duration of the healing, and transmission even after clinical relief, the first step is to provide sufficient isolation. Turkey has announced fourteen rules to protect the country against the spread of coronavirus, which has become a global problem. The rules include; hand hygiene, covering mouth and nose during 
coughing or sneezing, frequent ventilation of the environments, not touching the mouth, nose, and eyes with hands, keeping a distance of at least three steps between people who show signs of a cold, cancelling travels abroad, spending the first 14 days at home when returning from abroad, cleaning favorite surfaces daily with, disinfectant and detergent, avoiding sharing personal items such as towels, washing clothes at 60-90 degree temperature, avoiding close contact (handshaking or hugging), drinking plenty of fluids, eating a balanced diet, paying attention to sleep time, avoiding contact with the elderly and other people with chronic diseases when feeling cold symptoms, and contacting a healthcare provider when there are symptoms of continuous fever, cough, and difficulty in breathing.

\section{DIAGNOSIS}

After incubation, the symptoms of COVID-19 infection appear approximately 5.2 days later. ${ }^{6}$ The most common clinical symptoms at the onset of COVID-19 are fever, cough and fatigue; other symptoms are sputum production, shortness of breath, sore throat, headache, arthro-myalgia, diarrhea, anosmia, dysgeusia (dysfunction of the sense of taste), pleuritic pain, conjunctivitis, hemoptysis, dyspnea, and vomiting. 7,8

A chest CT imaging is of great value in the diagnosis of pneumonia-related with COVID19. Multiple ground-glass opacities are usually found at the peripheral lung, subpleural area, and both lower lobes in the early stage of COVID-19. Interlobular septal thickening and intralobular interstitial thickening are observed in the later stages." Air bronchograms and consolidations occur within 7-10 days after the infection progresses. Progression is associated with an excessive increase in inflammatory cytokines. ${ }^{10}$ Lung ultrasonography is useful in the diagnosis and monitoring of the people who are suspected or confirmed the COVID-19. We believe that lung ultrasonography is also important for non-invasive assessment and dynamic monitoring of lung lesions in patients with COVID-19.
The specific diagnosis of the COVID-19 is a molecular-based approach. Molecular tests on respiratory samples are the first line of methods to confirm suspected cases. Although other laboratory tests are usually non-specific, tests may show lymphopenia, hyperferritinemia, and elevated C-reactive protein (CRP), erythrocyte sedimentation rate (ESR), D-dimer, lactate dehydrogenase (LDH), alanin aminotransferase, aspartate transaminase, prothrombin time, creatinine, creatine phosphokinase. Procalcitonin levels are usually normal. Blood gas analysis normal in the early and mild stage, mild hypoxia in the mild to moderate stage, in the late stage, severe hypoxia with hypercapnia occurs. The need for intensive care at the hospitalization was in $25-30 \%$ of infected patients with COVID-19 in the published articles. Fatalities are more common in the elderly, and those have comorbidities. ${ }^{11}$

\section{MANAGEMENT}

Oxygen support through a nasal cannula or face mask is necessary for hypoxic patients. Noninvasive mechanical ventilation is indicated when severe hypoxia with hypercapnia occurs. Invasive mechanical ventilation should be avoided as much as possible, and intubation decisions should not be made early.

There are no specific antiviral drugs or vaccines against COVID- 19 for humans, at the time of writing this article. Some potential antiviral drugs like Nucleoside analogs and HIV-protease inhibitors are being administered to patients with COVID-19. A recent study shows that Favipiravir, which is guanine analog is a potential drug for the treatment of patients infected by COVID-19. ${ }^{12}$ According to our clinical experience, we consider Favipiravir to be the best choice among available antiviral medicines when severe pneumonia occurs in COVID-19 patients. Remdesivir is an adenine analog that is used in hundreds of COVID-19 patients in the United States and Europe. In their anecdote, Kupferschmidt $\mathrm{K}$ and Cohen J. reported that they benefit from remdesivir treatment in COVID patients. ${ }^{13}$ Ribavirin is also 
a guanine analog and has been used to treat patients with SARS or MERS. ${ }^{14}$

Studies have shown that the antiviral activity of chloroquine against the SARS, MERS, HIV, Ebola, Hendra, and Nipah viruses in vitro due to inhibiting endosomal acidification. ${ }^{15,16}$ Hydroxychloroquine and chloroquine also have immunomodulatory effects suppressing the TNF- $\alpha$ and IL-6. Gao et al. announce that chloroquine inhibits the exacerbation of COVID-19 in China. ${ }^{17}$ According to our clinic experience, after $800 \mathrm{mg}$ loading dose, Hydroxychloroquine $400 \mathrm{mg}$ per day for five days, was very useful in adult patients diagnosed with COVID-19 which have a ground-glass opacities in CT, especially when combined with azithromycin. Randomized controlled trials and evidence are required for these drugs to be considered part of standard therapy.

Although the role of corticosteroids is unproven in viral pneumonia associated with COVID-19, in case of an excessive immune response in patients, Chinese guidelines do recommend to low-to-moderate dose corticosteroids for a short time. ${ }^{18,19,20}$

In our clinical experience, when the Platelet to Lymphocyte Ratio (PLR) over the 200 value, the cytokine storm risk dramatically increases in the patient with COVID-19. In this case, corticosteroids $(1 \mathrm{mg} / \mathrm{kg} /$ day of prednisone or equivalent for 4-5 days) may be beneficial for preventing pulmonary fibrosis since controlling cytokine storm.

Disseminated intravascular coagulation (DIC) could be seen in any stage of the patients diagnosed with COVID-19, and this situation is associated with higher mortality and morbidity. ${ }^{21}$ If there are no contraindications, we have preferred all patients treated for COVID19 to use LMWH at the prophylaxis dose.

\section{Convalescent plasma}

Convalescent Plasma (CP) is a passive antibody therapy. The use of the patient's antibodybearing plasma, which develops and heals antibodies against a pathogen, is used in patients with active disease infected with that pathogen, called passive antibody therapy. The mechanisms of the $\mathrm{CP}$ include neutralizing the virus by direct binding, initiating virus elimination by complement activation, antibody-dependent cellular cytotoxicity, and / or phagocytosis. Passive antibody treatment, which is an old treatment method dating back to the 1890 s, is a fast but non-permanent treatment method. Examples of the use of CP in the 21st century are 2003 SARS, 2009 H1N1, 2012 MERS, and 2013 Ebola outbreaks. It is reported that the first CP in COVID-19 was collected in Wuhan on 1 February 2020 and given to a patient on 9 February $2020 .^{22}$ In the study conducted by Duan et al., $200 \mathrm{ml} \mathrm{CP}$ was administered to 10 patients on an average of 16,5 days. $^{23}$ It has been shown that the complaints of fever, cough, and shortness of breath decreased and oxygen saturation increased within three days after $\mathrm{CP}$ application with neutralizing antibody titers >1: 640 . Simultaneously with clinical improvement, an increase in lymphocyte count and a significant decrease in CRP values and a decrease in radiological findings of the lung at the end of a week were determined. One of the remarkable results of this study is that the neutralizing antibody titers were above 1: 640 in all patients 1-2 days after the application of $\mathrm{CP}$ and serum SARS-CoV-2 RNA was negative in 7 patients. Also, in this study, when the blood of CP donors were examined, neutralizing antibody titer in 39 of 40 donors found above 1: 160. In other words, it was supported by this study that neutralizing antibodies developed in the plasma of almost all of the recovered patients. The American Food and Drug Administration (FDA) announced on 24 March 2020 that CP approved its use in critically ill patients. ${ }^{24}$ In Turkey, The Ministry of Health published COVID-19 Convalescent Plasma Procurement and Clinical Use Guide in April 2020. ${ }^{25}$ This guide standardized the time of application, the patient group to receive, product characteristics, and donor criteria. (Box 1) According to the results of the studies, the time of giving $\mathrm{KP}$ is significant. The application time between 7.14.days that the patient has not yet developed 


\section{Box 1: Patient selection criteria for applying Convalescent Plasma.}

1. Definitive (molecular laboratory test positive) or strongly possible (clinical/radiological findings + , PCR expected) with a diagnosis of COVID-19

2. Over 18 years old

3. In the first 14 days of the disease, preferably 7-10 days after the onset of symptoms

4. Serum $\lg A$ level is normal

5. Patients with one of the critical level disease markers:

a. Respiratory Rate $\geq 30$ / min

b. Peripheral Oxygen Saturation $\mathrm{SPO}_{2} \leq$ 93\%

c. $\mathrm{P}_{\mathrm{a}} \mathrm{O}_{2} / \mathrm{FiO}_{2}<300 \mathrm{mmHg}$

d. Oxygen saturation $<90 \%$ despite nasal oxygen supply of 5 liters/minute and above

e. Partial oxygen pressure $<70 \mathrm{mmHg}$ despite nasal oxygen support of 5 liters/minute and above

f. Mechanical ventilation requirement

g. An increase of more than $50 \%$ lung infiltration within 24-48 hours

h. SOFA Score $\geq 2$

i. Blood lactate level $>2 \mathrm{mmol} / \mathrm{L}$

j. Need for a vasopressor

k. Patients who are expected to have rapid clinical progression, those with poor prognostic parameters (lymphopenia; CRP, ESR, ferritin, LDH, D-dimer height)

I. Organ failure, respiratory failure, septic shock table requiring intensive care condition

$\mathrm{PaO}_{2}$ : Partial pressure of oxygen

$\mathrm{F}_{\mathrm{i}} \mathrm{O}_{2}$ : The fraction of inspired oxygen

SOFA: Sepsis Related Organ Failure Assessment

CRP: C-reactive protein

ESR: Erythrocyte sedimentation rate

LDH: Lactate dehydrogenase

SOFA: Sepsis Related Organ Failure Assessment

the antibody response. is considered to be the most appropriate time, and this is also recommended like this in the guides. Another critical point other than the application time is the antibody titer in the given plasma. The optimal level of anti-SARS-CoV-2 neutralizing antibody titer was identified as 1:80 at directory of Turkey and >1: 320 at FDA guidelines. ${ }^{24,25} \mathrm{It}$ is collected from the donor in the amount of 200-600 $\mathrm{ml}$ (varies with the bodyweight of the donor) by the plasma apheresis method. It is an uncertain point how much the optimal plasma dose will be given to the patient. In general, 200 $\mathrm{ml}$ Units were defined in the studies, and an average of 1-2 $U$ plasma was applied to the patients. There is also no clear information about the duration of the activity of antibodies given with CP. It is estimated that this period can last from weeks to several months. Potential Risks of CP are similar to the risks of blood product transfusion.

As a result, there is currently no proven treatment method for COVID-19. Besides nonspecific antiviral, antimalarial treatments, $\mathrm{CP}$ treatment seems to be an excellent supportive treatment. This passive antibody treatment, which has been shown to be effective in previous epidemic periods, has been shown in studies that yield positive results in the COVID19 pandemic. It is expected that the results of the $\mathrm{CP}$ treatment, which was initiated recently in our country, will be announced soon. While the results of large-scale randomized clinical trials are expected, $\mathrm{CP}$ administration appears to be a fast and safe supportive therapy, especially in critical patient groups.

\section{CONCLUSION}

The outbreak of COVID-19 from China has become a potential threat to the general population and healthcare workers all around the world in a relatively short period. At the time of writing this article, 104.912 people have had a diagnosis with COVID-19, and 2.600 patients have had die in Turkey due to this virus. As a novel pathogen, knowledge about this virus very limited. No current specific effective antiviral therapy and vaccination for COVID-19, so we have to do strict quarantine protocols to prevent the spread of COVID-19 via the human-to-human. When we learn more about this novel virus and COVID-19 pandemic, the better we can do, that is why all official health authorities need to maintain monitoring COVID-19 outbreak.

It is necessary to share our knowledge and clinical practice with other specialists to find the right treatment to benefit our patients so, it looks like multidisciplinary management is the best approach. 
Until vaccines and specific medications are found, taking quarantine/isolation measures, diagnosing the disease early, seems to be a good option. Convalescent plasma therapy, which is using successfully in Turkey, is promising for COVID-19 patients.

\section{Conflict of interest: Nil}

Authors' contribution: Both authors took equal part in preparation of this manuscript.

\section{REFERENCES}

1. World Health Organization. Statement on the second meeting of the International Health Regulations (2005) Emergency Committee regarding the outbreak of novel coronavirus (2019-nCoV). Available from: https://www.who.int/newsroom/detail/30-01-2020-statement [Accessed April 20 2020].

2. World Health Organization. WHO Director-General's opening remarks at the media briefing on COVID-19 11 March 2020. Available from: https://www.who.int/dg/speeches/de tail/who- director-general-s-openingremarks [Accessed April 12 2020].

3. World Health Organization. Coronavirus disease 2019 (COVID19) Situation Report-90. Available from:

https://www.who.int/docs/defaultsource/coronaviruse/situationreports/20200419-sitrep-90-covid19.pdf?sfvrsn=551d47fd 4 . [Accessed April 20 2020].

4. Rothe $C$, Schunk M, Sothmann P, Bretzel G, Froeschl G, Wallrauch C, et al. Transmission of 2019-nCoV infection from an asymptomatic contact in Germany. N Engl J Med. 2020;382(10):970-1. [PubMed] DOI: 10.1056/NEJMc2001468

5. Hindson J. COVID-19: faecal-oral transmission? Nat Rev Gastroenterol Hepatol. 2020 Mar 25;17(5):259. [PubMed] DOI: 10.1038/s41575-020-0295-7

6. Li Q, Guan X, Wu P, Wang X, Zhou $\mathrm{L}$, Tong $\mathrm{Y}$, et al. Early transmission dynamics in wuhan, China, of novel coronavirus-infected pneumonia. N Engl J Med. 2020 Mar 26;382(13):1199-207. [PubMed] DOI: $10.1056 /$ NEJMoa2001316

7. Wang D, Hu B, Hu C, Zhu F, Liu X, Zhang $J$, et al. Clinical Characteristics of 138 Hospitalized Patients With 2019 Novel Coronavirus-Infected Pneumonia in
Wuhan, China. JAMA. 2020. [PubMed] DOI: 10.1001/jama.2020.1585

8. Chen N, Zhou M, Dong X, Qu J, Gong F, Han $Y$, et al. Epidemiological and clinical characteristics of 99 cases of 2019 novel coronavirus pneumonia in Wuhan, China: a descriptive study. Lancet. 2020;395(10223):507-13. [PubMed] DOI: 10.1016/S01406736(20)30211-7

9. Lei J, Li J, Li X, Qi X. CT imaging of the 2019 novel coronavirus (2019$\mathrm{nCoV}$ ) pneumonia. Radiology. 2020 Apr;295(1):18. [PubMed] DOI: 10.1148/radiol.2020200236

10. Chen N, Zhou M, Dong X, Qu J, Gong $F$, Han $Y$, et al. Epidemiological and clinical characteristics of 99 cases of 2019 novel coronavirus pneumonia in Wuhan, China: a descriptive study. Lancet. 2020;395(10223):507-13. [PubMed] DOI: 10.1016/S01406736(20)30211-7

11. Coronavirus Outbreak. Available from:

https://www.worldometers.info/coro navirus/ [Accessed April 22 2020].

12. Wang $M$, Cao R, Zhang $L$, Yang $X$, Liu J, Xu M, et al. 2020. Remdesivir and chloroquine effectively inhibit the recently emerged novel coronavirus (2019-nCoV) in vitro. Cell Res. 2020;30(3):269-71. [PubMed] DOI: 10.1038/s41422020-0282-0

13. Kupferschmidt K, Cohen J. Race to find COVID-19 treatments accelerates. Science. 2020;367(6485):1412-3. [PubMed] DOI:

10.1126/science.367.6485.1412

14. Al-Tawfiq JA, Momattin H, Dib J, Memish ZA. 2014. Ribavirin and interferon therapy in patients infected with the Middle East respiratory syndrome coronavirus: an observational study. Int J Infect Dis. 2014 Mar;20:42-6. [PubMed] DOI: $10.1016 /$ i.jij. 2013.12.003

15. Vincent MJ, Bergeron E, Benjannet S, Erickson BR, Rollin PE, Ksiazek TG, et al. Chloroquine is a potent inhibitor of SARS coronavirus infection and spread. Virol J. 2005;2:69. [PubMed] DOI: 10.1186/1743-422X-2-69

16. Keyaerts $E$, Vijgen $L$, Maes $P$, Neyts J, Van Ranst M. In vitro inhibition of severe acute respiratory syndrome coronavirus by chloroquine. Biochem Biophys Res Commun. 2004;323(1):264-8. [PubMed] DOI: 10.1016/j.bbrc.2004.08.085

17. Gao J, Tian Z, Yang X. Breakthrough: Chloroquine phosphate has shown apparent efficacy in treatment of COVID-19 associated pneumonia in clinical studies. Biosci Trends. 2020 Mar 16;14(1):72-3. [PubMed] DOI: 10.5582/bst.2020.01047

18. Russell CD, Millar JE, Baillie JK. Clinical evidence does not support corticosteroid treatment for 2019$\mathrm{nCoV}$ lung injury. Lancet. 2020;395(10223):473-5. [PubMed] DOI: $\quad 10.1016 / S 0140-$ 6736(20)30317-2

19. Shang L, Zhao J, Hu Y, Du R, Cao $B$. On the use of corticosteroids for 2019-nCoV pneumonia. Lancet. 2020;395(10225):683-4. [PubMed] DOI: $\quad 10.1016 / S 0140-$ 6736(20)30361-5

20. Zhao JP, Hu Y, Du RH, Chen ZS, Jin $Y$, Zhou $M$, et al. Expert consensus on the use of corticosteroid in patients with 2019nCoV pneumonia. Zhonghua Jie He $\mathrm{He} \mathrm{Hu}$ Xi Za Zhi. 2020;43:E007. [PubMed] DOI: 10.3760/cma.j.issn.1001$\underline{0939.2020 .0007}$ 
Turkish perspective of COVID-19

21. Tang N, Li D, Wang X, Sun Z. Abnormal coagulation parameters are associated with poor prognosis in patients with novel coronavirus pneumonia. J Thromb Haemost. 2020 Apr;18(4):844-7 [PubMed] DOI: $10.1111 /$ ith. 14768

22. China puts 245 COVID-19 patients on convalescent plasma therapy. News release. Xinhua. 28 February, 2020. Available from: http://www.xinhuanet.com/english/2 020-02/28/C_138828177.htm. [Accessed April 26 2020].

23. Duan K, Liu B, Li C, Zhang H, Yu T, Quet $J$, et al. The feasibility of convalescent plasma therapy in severe COVID-19 patients: a pilot study. medRxiv. 2020;(8):2020.03.16.20036145. DOI: $10.1101 / 2020.03 .16 .20036145$
24. FDA. Investigational covid-19 convalescent plasma-emergency INDs. Available from: https://www.fda.gov/media/136470/ download [Accessed April 26 2020].

25. Turkish Ministry of Health Immune Plasma Guidelines, 2020. Available from:

https://dosyamerkez.saglik.gov.tr/Ek lenti/37163,covid-19. (Accessed on 25 April 2020) 